\title{
Strategi Pengelolaan Kampung Betawi Setu Babakan Sebagai Daya Tarik Wisata Di Jakarta Selatan
}

Nurul Hayati a, 1 Ida Ayu Suryasih a, 2

1nurulhayatiemdi@gmail.com,2idaayusuryasih@unud.ac.id

a Program Studi Sarjana Destinasi Pariwisata, Fakultas Pariwisata,Universitas Udayana, Jl. Dr. R. Goris, Denpasar, Bali 80232 Indonesia

\begin{abstract}
Tourist Attractions in Indonesia can be found in the form of natural, art and cultural traditions. They can also be developed and utilized for sustainable tourism development. This culture tourism needs to be developed with the aim of preserving the culture itself. The aim of the organization is to preserve culture which is can be achieved effectively and efficiently by implementing a good management system. A good management can be improved if the components are well functioned. A good management has managerial functions, namely planning, organizing, directing and supervising.

This research was conducted at the Setu Babakan Betawi Cultural Village,because it is the only tourist village that still exists in Jakarta that develops the concept of cultural tourism.This research uses observation, interview and documentation techniques. The informants were the staff of the Setu Babakan Betawi Cultural Village consists of service and information and administrative sub-section employees.

The results of the study show that the management in the Betawi Cultural Village has already been conducted optimally, however there are still some inhibiting factors felt at the Setu Babakan such as structural and operational obstacles. In this study it is also discuss SWOT analysis. The strategies have been formulated such as using a land as an integrated tourist area, adding tourist attractions, preventing environmental pollution, and conduct counseling on the preservation of Betawi culture.
\end{abstract}

Key words: cultural tourism, management functions, inhibiting factors, Betawi Village Setu Babakan.

\section{PENDAHULUAN}

Daya tarik wisata di Indonesia berupa kekayaan alam maupun seni dan tradisi budaya dapat dikembangkan dan dimanfaatkan demi pembangunan pariwisata berkelanjutan. Pengembangan daya tarik wisata tersebut apabila didukung dengan pengembangan sarana maupun prasarana akan lebih berpengaruh untuk meningkatkan jumlah kunjungan wisatawan. Indonesia memiliki berbagai macam potensi wisata yang dapat menarik perhatian wisatawan nusantara maupun mancanegara. Salah satunya adalah Kota Jakarta. Ibu Kota Jakarta selain dikenal sebagai pusat pemerintahan dan industri juga dikenal sebagai wilayah yang memiliki banyak potensi sebagai destinasi tujuan wisata seperti wisata alam, berupa pantai dan hutan mangrove. lalu ada wisata budaya berupa museum dan pasar seni betawi, tetapi Kota Jakarta lebih didominasi oleh wisata buatan diantaranya museum, waterboom, taman bermain, dan kebun binatang. Hanya sedikit wisatawan yang tahu bahwa di ujung selatan kota metropolitan, masih terdapat perkampungan tradisional dari komunitas Betawi yang terawat dengan baik yang terkenal dengan sebutan perkampungan Betawi Setu Babakan.

Kampung Betawi Setu Babakan dibangun untuk tujuan pelestarian dan pengembangan kebudayaan Betawi secara berkesinambungan dan telah ditetapkan oleh Pemerintah Jakarta pada tanggal 20 Januari 2000. Perkampungan yang berada di pinggiran Jakarta Selatan ini merupakan jenis wisata budaya yang menyediakan berbagai atraksi wisata dan kebiasaan masyarakat Betawi asli sehingga dapat menarik minat wisatawan.

Jika ingin mendapatkan hasil maksimal dalam proses pengelolaan, maka harus memiliki komponen yang baik di dalam nya. Komponenkomponen tersebut harus bekerja dengan baik untuk mendapatkan hasil yang maksimal. Di dalam pengelolaan yang hendak di capai, perlu dilakukan fungsi-fungsi pengelolaan yaitu 
perencanaan, pengorganisasian, pengarahan, dan pengawasan. Masing-masing fungsi akan saling berkaitan dan menjadi satu kesatuan yang tidak dapat terpisahkan. Suatu struktur organisasi akan dapat mencapai tujuan yang diinginkan apabila mampu merencanakan tujuan-tujuan yang akan di capai, mampu mengorganisir sumber daya termasuk manusia dengan baik, melaksanakan rencana yang telah dibuat serta mengawasi pelaksanaan agar sesuai dengan semestinya sehingga program yang telah dibuat dapat tercapai dengan baik. Dengan pengelolaan yang tepat maka tujuan organisasi untuk melestarikan kebudayaan Betawi dapat tercapai secara efektif dan efisien. Berlandaskan pada fenomena tersebut, maka dilakukan penelitian mengenai pengelolaan di Kampung Betawi Setu Babakan dengan menggunakan pendekatan manajemen

\section{TINJAUAN PUSTAKA}

\subsection{Telaah Penelitian Sebelumnya}

Penelitian yang dilakukan oleh Digna Merian Andriani (2015) dalam jurnal yang berjudul "Pengelolaan Desa Wisata Blimbing menjadi Pariwisata Berkelanjutan di Kecamatan Blimbing Pupuwan, Tabanan, Bali". Penelitian ini memiliki kesamaan fokus yaitu membahas tentang hambatan dalam pengelolaan daya tarik wisata dan menggunakan analisis SWOT.

\subsection{Kajian Konsep}

Konsep yang berkaitan dengan rumusan masalah pertama, yaitu konsep wisata budaya. Menurut Damardjati (2001) wisata budaya merupakan kegiatan wisata berupa hasil seni budaya setempat, misalnya adat istiadat, upacara keagamaan, tata hidup masyarakat, peninggalan sejarah, hasil seni dan kerajinan rakyat. Konsep kedua yang berkaitan dengan penelitian ini yaitu konsep hambatan.

Menurut Tosun (2002) setiap pengelolaan juga terdapat faktor penghambat yang dapat dibagi menjadi tiga tipe yaitu keterbatasan operasional, keterbatasan struktural dan keterbatasan budaya. Keterbatasan operasional meliputi standarisasi administrasi publik pariwisata, serta kurangnya koordinasi dan informasi. Kemudian Keterbatasan struktural meliputi sikap profesional, kurangnya keahlian, dominasi kaum elit, kurangnya sistem hukum yang tepat, kurangnya sumber daya manusia yang terlatih, partisipasi masyarakat, kurangnya sumber daya keuangan karena biaya yang relatif tinggi. Selanjutnya, Keterbatasan budaya meliputi faktor apatis atau rendahnya tingkat kesadaran dalam masyarakat dalam kepariwisataan. Jadi yang dimaksud hambatan dalam penelitian ini terdiri dari faktor internal dan ekternal. Faktor internal meliputi tentang budaya dan faktor eksternal meliputi tentang keterbatasan operasional dan struktural.

\section{METODE PENELITIAN}

Penelitian ini dilakukan di Kampung Betawi Setu Babakan, alasannya karena Kampung Betawi Setu Babakan merupakan satu-satunya perkampungan betawi yang masih ada di Jakarta, maka pengelolaan yang tepat harus dijalankan agar budaya betawi tidak hilang begitu saja. Penelitian ini menggunakan data kualitatif yaitu data mengenai gambaran umum, badan organisasi, jobdesc, dan aktivitas yang ada di PBB Setu Babakan. Data primer dari penelitian ini didapat dari subjek penelitian atau data data yang diperoleh secara langsung dari responden yang sudah di tentukan (Arikunto, 2010) mengenai mangemen pengelolaan di PBB Setu Babakan. Sedangkan data sekunder dari penelitian ini merupakan data yang di dapat dari orang lain (Sugiyono, 2014) yaitu mengenai sejarah, jenis aktivitas, struktur organisasi dan data karyawan di PBB Setu Babakan. Penelitian ini menggunakan teknik pengumpulan data observasi, wawancara, dokumentasi, dan studi kepustakaan. Untuk menentukan informan peneliti menggunakan teknik purposive sampling yaitu informan yang sudah ditentukan dengan pertimbangan tertentu. Sedangkan analisis data yang digunakan analisis SWOT untuk mengetahui keunggulan dan kekurangan di PBB Setu Babakan.

\section{HASIL DAN PEMBAHASAN}

Melalui SK Gubernur No. 9 Tahun 2000 Perkampungan Setu Babakan ditetapkan sebagai kawasan Cagar Budaya Betawi. Setelah itu Kampung Setu Babakan di resmikan oleh 
Gubernur DKI Jakarta, Sutiyoso sebagai kawasan Cagar Budaya Betawi pada tahun 2004. Dalam upaya untuk pelestarian budaya Betawi supaya tidak hilang oleh perkembangan zaman, maka wisata budaya di Perkampungan Budaya Betawi Setu Babakan ini perlu dilestarikan. Hal ini yang terus diupayakan oleh pengelola Kampung Betawi Setu Babakan. Wisatawan yang berkunjung masih bisa merasakan kebudayaan betawi yang sangat kental, misalnya wisatawan masih bisa menikmati berbagai pagelaran seni tradisional betawi antara lain gambang kromong, lenong, orkes samrah, beladiri beksi, dan tanjidor serta pertunjukan ondel-ondel yang selalu di pentaskan kepada para pengunjung setiap akhir pekan di sebuah panggung terbuka berukuran 60 meter persegi. Selain itu, wisatawan juga dapat mencicipi makanan khas Betawi seperti soto mie, ketoprak, bir pletok, kerak telor, dan dodol betawi. Di kawasan ini juga dibangun Rumah Adat Betawi seperti Rumah Gudang, Rumah Joglo, dan Rumah Kebaya. Kawasan Setu Babakan merupakan satu-satunya kampung pelestarian budaya Betawi yang tersisa, oleh karena itu pengelolaan harus dilakukan secara optimal baik dari segi pelestarian aset budaya, infrastruktur khas betawi, serta kesenian tradisional agar budaya betawi tetap hidup ditengah arus modernisasi.

\subsection{Pengelolaan Wisata Budaya di Perkampungan Budaya Betawi Setu BaBakan}

Setelah di resmikannya PBB Setu Babakan sebagai kawasan pelestarian Budaya Betawi pada tahun 2004, maka berdasarkan Peraturan Daerah Nomor 3 tahun 2005 maka di bentuklah organisasi untuk mengelola Setu Babakan yang dinamakan Unit Pengelola Kawasan Perkampungan Budaya Betawi (UPK PBB). Unit ini merupakan pelaksana teknis di lapangan yang bertanggung jawab langsung dibawah PEMDA Provinsi DKI Jakarta dalam melaksanaan kegiatan pelestarian Perkampungan Budaya Betawi (PBB). Tugas lembaga pengelola ini adalah untuk menjaga dan mempertahankan tata kehidupan dan nilai kebudayaan masyarakat Betawi, mengembangkan seni budaya Betawi, serta memanfaatkan potensi lingkungan fisik, baik potensi alam maupun buatan yang bertema
Betawi. Berikut akan dijelaskan mengenai pengelolaan PBB Setu Babakan berdasarkan fungsi manajemen yaitu planning, organization, actuating dan controlling.

Perkampungan Budaya Betawi Setu Babakan memiliki perencanaan serta tujuan yang akan dicapai dalam kurun waktu tertentu. Pengelola tidak menargetkan jumlah kunjungan wisatawan perbulannya, karena PBB Setu Babakan kontennya bukan wisata tapi pengenalan budaya. Selain itu pengelola juga memiliki rencana jangka panjang yaitu dengan dibangunnya Zona B, Zona C, dan Zona Pengembangan. Proses pengawasan dilakukan Kepala Unit dengan cara pendekatan secara kekeluargaan pada setiap pegawai. Dalam menjalankan tugas-tugasnya untuk mencapai keberhasilan diperlukan dukungan para pekerja yang kompeten serta berkualitas. Oleh sebab itu dalam merekrut pegawai PBB Setu Babakan dilakukan dengan pola rekrut PNS (Pegawai Negri Sipil) seperti biasanya, karena berada dibawah ikatan Dinas Pariwisata dan Kebudayaan (PEMDA). Saat ini pegawai UPK PBB Setu Babakan yang berasal dari PEMDA berjumlah 12 orang. Menurut wawancara dengan pengelola perlu penambahan staff lagi, khususnya pada bidang pelaksanaan prasarana dan sarana. Hal ini dilihat dari perkembangan PBB Setu Babakan yang terus meningkat, jadi beban kerja yang dirasakan lebih berat dan tidak sebanding dengan volume wilayah yang begitu luas.

Adapun pengelolaan yang dilakukan UPK PBB Setu Babakan adalah melakukan penertiban para pedagang yang tersebar di sekitaran Setu Babakan. Pengelolaan dari segi aksesibilitas yaitu dengan memperbaiki jalan dan pembuatan jembatan gantung. Selanjutnya pengelolaan yang dilakukan di Zona A dan Embrio berupa pengelolaan rumah adat khas betawi, gedung kuliner dan museum Betawi yaitu dengan cara tetap menjaga kebersihan dan melakukan pemeliharaan fasilitas, sarana dan prasarana yang ada. Setelah itu ada juga pengelolaan jadwal pertunjukan seni yang dilaksanakan setiap akhir pekan di Zona A Setu Babakan. Dalam pelaksanaan pengelolaan, Kepala Unit membimbing dan mengutarakan secara langsung, memotivasi pegawainya agar semangat kerja, dan 
memantau secara langsung aktivitas pegawainya setiap saat. Dengan demikian kegiatan pengelolaan dapat berjalan secara maksimal sesuai dengan tujuan bersama. Pengawasan dalam hal pemasukan dan pengeluaran dilakukan di setiap akhir tahun dengan mengirim hasil rincian ke Badan Pengawasan Keuangan Prov DKI Jakarta. Selain itu setiap bulannya juga diadakan rapat tentang penyediaan dan penambahan sarana prasarana, pengeluaran dan pemasukan UPK, rencana pengembangan dan pembangunan serta kualitas kerja para pegawai di UPK PBB Setu Babakan.

\subsection{Faktor Penghambat dalam Pengelolaan}

Setu Babakan merupakan kawasan cagar budaya yang memiliki luas lahan lebih kurang 289ha. Kawasan ini dikelola oleh lembaga pengelola Kampung Betawi Setu Babakan yang dalam pelaksanaan nya menjalin kemitraan dan kerjasama dengan instansi pemerintah, SKPD/UKPD, masyarakat dan swasta. Berdasarkan wawancara yang dilakukan terdapat beberapa kendala yang dihadapi Unit Pengelola Kawasan PBB Setu Babakan yaitu :

1) Kendala struktural : Sumber daya manusia yang tidak mencukupi dalam menajemen pengelolaan. Meskipun saat ini setiap pegawai sudah menjalankan tugasnya sesuai dengan fungsinya masing-masing, namun tetap dibutuhkan jumlah sumber daya manusia yang lebih besar, khususnya dalam bidang pelaksana prasarana dan sarana. Hal ini dilihat dari Perkembangan PBB Setu Babakan yang terus meningkat sehingga beratnya beban kerja yang dirasakan, tidak sebanding dengan volume wilayah yang begitu luas.

2) Kendala operasional : Unit Pengelola PBB Setu Babakan juga mengalami kesulitan berkoordinasi dengan instansi maupun SKPD/UKPD pembantu seperti dengan Dinas Sumber Daya Air, Dinas Binamarga, maupun Dinas UMKM Perdagangan dikarenakan kendala operasional. Misalnya pada saat dibutuhkan, alat untuk pengerukan Setu milik Dinas Sumber Daya Air digunakan oleh dinas lain. Sehingga pelaksanaan pengerukan harus ditunda dan UPK PBB harus menunggu dalam waktu yang cukup lama atau contoh lainnya, seperti dalam hal penertiban pedagang kaki lima, harus berkoordinasi dulu dengan Dinas UMKM Perdagangan, itupun pelaksanaan pengelolaan tidak langsung dilakukan karena harus menunggu lagi kebijakan dari atas yang lumayan memakan waktu lama.

\subsection{Analisis SWOT :}

1) Kekuatan (Strength)

- Mempunyai lahan yang luas untuk dikelola

- Sumber daya manusia yang berkompeten dalam pengelolaan

- Memberi kebebasan untuk warga sekitar berjualan di UPK PBB Setu Babakan

- Sebagai sarana yang berperan dalam menyediakan kesempatan bagi sanggarsanggar Betawi

2) Kelemahan (Weakness)

- Pengelolaan serta pemanfaatan lahan yang belum menyeluruh

- Media promosi yang belum maksimal

- Belum adanya kerjasama antara UPK PBB dengan masyarakat terkait pengelolaan wisata kuliner,wisata air dan kerajinan tangan

- Masih kurangnya sumber daya manusia dalam manejemen pengelolaan

3) Peluang (Opportunity)

- Lahan yang luas dapat dijadikan sebagai wisata terpadu

- Mendatangkan wisatawan lokal maupun asing

Meningkatkan pendapatan dan taraf hidup masyarakat

- Dapat memperkenalkan kebudayaan dan kesenian masyarakat

4) Ancaman (threat)

- Kurangnya ketertarikan masyarakat untuk datang ke Setu Babakan karena atraksi yang kurang menarik

- Pencemaran Lingkungan

- Penyempitan lahan

- Banyaknya pilihan destinasi modern di wilayah Jakarta Selatan

Selanjutnya diuraikan setiap strategi yang akan digunakan dalam pengembangan daya tarik 
wisata Kampung Betawi Setu Babakan dilihat dari:

1. Strategi S-O yang menggunakan kekuatan (strength) untuk menghasikan peluang (opportunities), yaitu: 1) lahan yang luas dapat dimanfaatkan oleh UPK PBB untuk mengembangkan kawasan wisata terpadu yang yang tidak hanya menyediakan lahan rekreasi tapi juga sebagai pusat edukasi serta menyediakan hiburan khas Betawi; 2) perbaikan dan penambahan fasilitas penunjang harus dilakukan; 3) membangun kios-kios serta menyediakan lahan yang lebih luas bagi para pedagang untuk berjualan; 4) melibatkan para pengunjung untuk ikut serta mengikuti kesenian tradisional bersama seniman-seniman betawi.

2. Srategi S-T adalah strategi yang muncul karena adanya kekuatan (strength) yang digunakan untuk mengatasi ancaman (threats), yaitu: 1) dengan menyediakan atraksi wisata yang lebih menarik seperti penyewaan sepeda, pemotretan dengan baju adat betawi ataupun mengajarkan pengunjung tari tradisonal betawi; 2) menyediakan tempat sampah di setiap sudut Setu Babakan; 3) pembangunan Setu Babakan harus dilakukan sesuai dengan zonasi yang telah ditentukan serta tetap memperhatikan tata ruang yang ada; 4) rutin mengadakan berbagai pertunjukan seni yang lebih menarik agar para pengunjung tidak bosan untuk datang ke Setu Babakan.

3. Strategi W-O merupakan strategi pemanfaatan peluang (opportunities) dengan meminimalisir kekurangan (weakness), dengan cara : 1) pemanfaatan lahan yang luas untuk mengembangkan kawasan ekowisata; 2) melakukan promosi melalui media sosial dan bantuan Public Relation (PR); 3) memfasilitasi kegiatan cultural visit kepada para pengrajin dengan menyediakan jadwal khusus yang dapat dipilih oleh calon wisatawan untuk dapat mengikuti workshop kerajinan serta batik betawi dimana pengrajin lokal yang menjadi mentor nya; 4) membuat panggung indoor yang berguna bagi seniman agar tidak kehujanan saat tampil di Setu Babakan.

4. Strategi W- $\mathrm{T}$ adalah strategi untuk meminimalkan kelemahan (weakness) untuk menghindarkan ancaman (threats) yang dapat dilakukan dengan cara : 1) melakukan penyuluhan dan sosialisasi tentang pelestarian kebudayaan betawi; 2) melakukan kerjasama dengan agent travel untuk menyediakan paket wisata budaya ke PBB Setu Babakan; 3) membuat aturan agar tidak membuang sampah sembarangan atau mengadakan kegiatan daur ulang sampah dengan melibatkan warga sekitar; 4) pengenalan budaya bagi generasi muda dapat dilakukan dengan membangun sekolah budaya betawi.

\section{SIMPULAN DAN SARAN \\ 5.1 Simpulan}

Simpulan dalam penelitian ini yaitu pengelolaan di PBB Setu Babakan sudah berjalan dengan baik, yaitu :

a) Perencanaan yang dilakukan UPK PBB Setu Babakan sudah berjalan dengan baik serta sudah ada upaya dalam pembangunan namun masih memiliki beberapa kendala seperti kendala operasional dan struktural.

b) Pengorganisasian sudah berjalan dengan baik. Seluruh pegawai dilibatkan, serta dalam pengelolaan mereka sudah sesuai dengan tugas dan kewajibannya masingmasing walaupun masih terkendala kurangnya sumber daya manusia dalam pengelolaan

c) Penggerakan para pegawai dilakukan langsung oleh Kepala Unit, dengan cara memotivasi mereka serta turun langsung ke lapangan. Dilihat dari pelaksanaan pengelolaan telah berjalan dengan baik

d) Pengawasan para pegawai dan administrasi dilakukan langsung oleh Kepala Unit dan sudah dilakukan dengan baik.

Selain itu terdapat beberapa faktor penghambat dalam pengelolaan PBB Setu seperti kendala struktural yaitu masih kurang nya sumber daya manusia dalam mangemen pengelolaan, hal ini dapat dilihat dari beratnya beban kerja yang dirasakan pegawai tidak 
sebanding dengan volume wilayah yang begitu luas. Selain itu terdapat juga kendala dari segi operasional yaitu koordinasi yang masih lambat antara pengelola dengan pihak SKPD/UKPD pembantu. Hal ini dapat dilihat dari lambatnya proses penyediaan alat-alat pengelolaan di Kampung Betawi Setu Babakan.

Strategi pengembangan Kampung Setu Babakan dilihat dari analisis SWOT yaitu:

1) Strategi S-O dengan memanfaatkan lahan yang luas untuk mengembangkan kawasan wisata terpadu yang yang tidak hanya menyediakan lahan rekreasi tapi juga sebagai pusat edukasi serta menyediakan hiburan khas betawi.

2) Strategi S-T yaitu PBB Setu Babakan perlu menyediakan atraksi wisata yang lebih menarik seperti penyewaan sepeda, pemotretan dengan baju adat betawi ataupun mengajarkan pengunjung tari tradisonal Betawi

3) Strategi W-O dengan cara mencegah pencemaran lingkungan perlu disediakan tempat sampah di setiap sudut Setu Babakan. Selain itu lahan yang luas juga dapat dimanfaatkan untuk mengembangkan kawasan ekowisata. Hal ini didukung oleh kenampakan alam serta vegetasi yang terdapat di Setu Babakan.

4) Strategi $W$ - $T$ dapat dilakukan dengan melakukan penyuluhan dan sosialisasi tentang pelestarian kebudayaan betawi. Selain itu juga dapat dilakukan kerjasama dengan agent travel untuk menyediakan paket wisata budaya ke PBB Setu Babakan.

\subsection{SARAN}

Diharapkan untuk kedepannya pengelola dapat melakukan koordinasi secara berkesinambungan dengan para SKPD/UKPD yang membantu pengelolaan, Selain itu pengelola juga bisa memperkerjakan para pegawai magang / outsoursing untuk membantu meringankan pelaksanaan pengelolaan di PBB Setu Babakan.

\section{DAFTAR PUSTAKA}

Andriani, M. A. "Pengelolaan Desa Wisata Belimbing Menuju Pariwisata Berkelanjutan Kecamatan Pupuwan, Kabupaten Tabanan, Bali." Jurnal Destinasi Pariwisata 3.1 (2015): 17-23.

Arikunto, S. 2010. Penelitian Suatu Pendekatan Praktik. Jakarta: PT Rinneka Cipta

Damardjati, R. S. Istilah-istilah Dunia Pariwisata. Jakarta : Pradnya Paramitha

Peraturan Daerah Nomor 3 Tahun 2005 Tentang Dibentuknya Organisasi dan Tata Kerja Unit Pengelola Kawasan Perkampungan Budaya Betawi

Sugiyono.2014. Metode Penelitian Kuantitatif Kualitatif dan R\&D. Bandung : Alfabeta

Surat Keputusan Gubernur Nomor 9 Tahun 2000 tentang Penetapan Perkampungan Betawi Setu Babakan sebagai kawasan Cagar Budaya Betawi di Jakarta Selatan

Tosun, C. 2002. Limits of Community Participation in the Tourism Development Process in Developing Countris : Tourism Management. 